\title{
Behandling av cerebrovaskulære sykdommer i slagenhet
}

\author{
Sammendrag \\ Bakgrunn. Utviklingen av slagenheter \\ de siste tiårene har ført til endret hånd- \\ tering av pasienter med hjerneslag. \\ Målet for denne studien er å analysere \\ klinisk presentasjon, behandling og \\ utfall $i$ en uselektert gruppe pasienter \\ innlagt $i$ en behandlingsorientert akutt- \\ slagenhet.
}

Materiale og metode. Alle pasienter med mistenkt cerebrovaskulær sykdom ble innlagt i slagenheten for øyeblikkelig hjelp. Pasienter med sikker cerebrovaskulær sykdom i perioden 1.2. 2006-30.4. 2009 ble prospektivt inkludert i studien. De som viste seg å ha andre diagnoser, ble ikke inkludert, men prospektivt registrert i en tremånedersperiode.

Resultater. 49,8\% av pasientene hadde andre diagnoser enn akutt hjerneslag. Av 1101 pasienter med sikker cerebrovaskulær sykdom hadde $10 \%$ transitorisk iskemisk anfall (TIA), 79 \% infarkt og $10 \%$ blødning. Ved innleggelsen hadde $72 \%$ ingen eller lette nevrologiske utfall. Etter én uke var $63 \%$ selvhjulpne, $25 \%$ hadde behov for lengre rehabilitering og $10 \%$ var helt pleietrengende.

Fortolkning. Flertallet av pasientene i vår studie har lette utfall og fremfor alt behov for nøyaktig diagnostisk avklaring og for akutt og sekundærprofylaktisk behandling. For et mindretall av pasientene er rehabilitering en viktig del av opplegget.

\author{
Lars Thomassen \\ Itho@haukeland.no \\ Nevrologisk avdeling \\ Haukeland universitetssykehus \\ 5021 Bergen \\ og \\ Institutt for klinisk medisin \\ Universitetet i Bergen \\ Ulrike Waje-Andreassen \\ Halvor Næss \\ Jan Brøgger \\ Nevrologisk avdeling
}

Haukeland universitetssykehus

Utviklingen av slagenheter de siste 20-25 år har fundamentalt endret håndteringen av pasienter med hjerneslag. Slagenheten som behandlingskonsept har et solid vitenskapelig grunnlag, og resultatene er imponerende: Pasientene har større sannsynlighet for å overleve, komme tilbake til hjemmet og å oppnå selvstendighet hvis de behandles $i$ en slagenhet istedenfor i en generell sengepost (1-3).

Etter at slagenhetsstudiene ble gjennomført, har imidlertid diagnostikk og behandling i de første timene etter symptomdebut på ny blitt revolusjonert for dem med akutt hjerneslag, og da spesielt pasienter med hjerneinfarkt. Akuttfasen som begrep har fătt et endret innhold, og slagenheten har fått endrede oppgaver.

Målet for denne studien er å analysere klinisk-nevrologiske utfall, diagnostikk, behandling og sjudagersutfall i en uselektert pasientpopulasjon med mistenkt akutt cerebrovaskulær sykdom innlagt i en slagenhet. Vi ønsket også å relatere aspekter ved denne studien til tidligere rehabiliteringsorienterte slagenhetsstudier.

\section{Materiale og metode}

Alle pasienter med mistenkt cerebrovaskulær sykdom innlegges $i$ vår slagenhet for øyeblikkelig hjelp. Pasientene kan innlegges uten forutgående legeundersøkelse. Slagenheten tar imot alle pasienter fra eget nedslagsfelt med mistenkt cerebrovaskulær sykdom, uavhengig av alder (representativ populasjon). I tillegg tar slagenheten imot pasienter under 60 år med mistenkt cerebrovaskulær sykdom som sokner til Haraldsplass Diakonale Sykehus i Bergen. Den totale populasjonen i denne studien omfatter begge grupper.
Pasienter med sikker cerebrovaskulær sykdom, dvs. transitorisk iskemisk anfall (TIA), hjerneinfarkt eller hjerneblødning, innlagt i perioden 1.2. 2006-30.4. 2009 ble prospektivt inkludert i studien, og pasientdata ble prospektivt lagt inn i Bergen Stroke Registry. Pasienter som viste seg å ha andre diagnoser ble ekskludert, men i en tilfeldig tremåneders periode $(1.2 .-30.4$. 2009) ble deres utskrivningsdiagnoser registrert med tanke på analyse av differensialdiagnoser.

Diagnosene som ligger til grunn for analysene er basert på full cerebrovaskulær utredning i løpet av sykehusoppholdet. Diagnosen stilles av nevrolog. Når en pasient innlegges i slagenheten, benytter sykepleier og lege rutinemessig en arbeidsbok med skåringstabeller, tidsforløp, behandling etc., som følger pasienten under oppholdet. Arbeidsboken representerer kildedata for Bergen Stroke Registry. Data kvalitetssikres av én av studienevrologene (HN).

Avdelingens metodebok for behandling av akutte cerebrovaskulære sykdommer ble benyttet som studieprotokoll (4). Nevrologiske utfall kvantiteres ved innkomst av vakthavende nevrolog og under forløpet av nevrolog eller slagsykepleier med National Institutes of Health Stroke Scale (NIHSS), hvor 0-7 poeng betyr lett slag, 8-14 moderat slag og $\geq 15$ alvorlig slag (5). Klinisk korttidsresultat vurderes den sjuende dagen etter innleggelse eller ved utskrivning (hos pasienter som skrives ut tidligere enn sju dager etter innleggelse). Funksjon i dagliglivets basale aktiviteter (ADL) skåres av slagsykepleier med Barthels ADL-indeks (BI), der skår > 95 indikerer selvhjulpenhet, 60-95 potensiell selvhjulpenhet, og $<60$ indikerer langtidsbehov

\section{Hovedbudskap}

- Nær annenhver pasient som innlegges for mulig slag viser seg å ha andre diagnoser

- Flertallet av slagpasientene har lette hjerneslag og er selvhjulpne i løpet av 1 uke

- For flertallet er rask diagnostikk, akuttbehandling og sekundærprofylakse det viktigste

- En tredel av pasientene har større hjerneslag og har behov for lengre rehabilitering $\mathrm{i}$ en slagenhet 
Tabell 1 Karakteristika ved 1101 pasienter innlagt med cerebrovaskulær sykdom

\begin{tabular}{|c|c|c|c|c|c|c|c|c|c|}
\hline \multirow[b]{2}{*}{ Totalt } & \multicolumn{2}{|c|}{$\begin{array}{c}\text { TIA } \\
\text { n (\%) }\end{array}$} & \multicolumn{2}{|c|}{$\begin{array}{c}\text { Infarkt } \\
\text { n (\%) }\end{array}$} & \multicolumn{2}{|c|}{$\begin{array}{c}\text { Blødning } \\
\text { n (\%) }\end{array}$} & \multicolumn{2}{|c|}{ Totalt } & \multirow[t]{2}{*}{ P-verd } \\
\hline & 120 & $(10,9)$ & 873 & $(79,3)$ & 108 & $(9,8)$ & 1101 & $(100)$ & \\
\hline Kvinner & 49 & $(40,9)$ & 373 & $(42,7)$ & 42 & $(38,9)$ & 464 & $(42,1)$ & 0,71 \\
\hline Menn & 71 & $(59,1)$ & 500 & $(57,3)$ & 66 & $(61,1)$ & 637 & $(57,9)$ & \\
\hline$<60 a ̊ r$ & 21 & $(8,8)$ & 200 & $(83,7)$ & 18 & $(7,5)$ & 239 & $(21,7)$ & 0,17 \\
\hline$>60 \mathrm{ar}$ & 99 & $(11,5)$ & 673 & $(78,1)$ & 90 & $(10,4)$ & 862 & $(78,3)$ & \\
\hline
\end{tabular}

Tabell 2 Etiologisk klassifisering etter TOAST-kriteriene hos 992 pasienter med cerebral iskemi

\begin{tabular}{|c|c|c|c|c|c|c|}
\hline \multirow{2}{*}{$\begin{array}{l}\text { Etiologi } \\
\text { Aterosklerose }\end{array}$} & \multicolumn{2}{|c|}{$\begin{array}{c}\text { TIA } \\
\text { n (\%) }\end{array}$} & \multicolumn{2}{|c|}{$\begin{array}{c}\text { Infarkt } \\
\text { n (\%) }\end{array}$} & \multicolumn{2}{|c|}{$\begin{array}{l}\text { Totalt } \\
\mathrm{n}(\%)\end{array}$} \\
\hline & 30 & $(25,0)$ & 121 & $(13,9)$ & 151 & $(15,2$ \\
\hline Kardiogen emboli & 17 & $(14,2)$ & 236 & $(27,1)$ & 253 & 125,5 \\
\hline Mikroangiopati & 6 & $(5,0)$ & 138 & $(15,8)$ & 144 & 114,5 \\
\hline Annen årsak & 1 & $(0,8)$ & 27 & $(3,1)$ & 28 & 12,8 \\
\hline Flere årsaker/ukjent & 66 & $(55,5)$ & 350 & $(40,1)$ & 416 & 141,9 \\
\hline
\end{tabular}

for hjelp. Funksjonelt globalt resultat skåres av slagsykepleier med modifisert Rankins skala (mRS) (6), der skår $0-2$ betyr uavhengighet, 3-5 avhengighet og 6 betyr død.

Alle pasientene vurderes klinisk i akuttmottaket med henblikk på trombolytisk behandling intravenøst eller intraarterielt (7) eller embolektomi (8). Umiddelbart etter innleggelsen blir pasientene utredet med CT. Pasienter som innlegges innen seks timer etter symptomdebut får også CT-angiografi (9). Flertallet av pasientene utredes med MR (10, 11) og MR-angiografi innen 24 timer. Alle utredes med dupleks ultralydundersøkelse av halsarterier og intrakraniale arterier (12) innen 24 timer. Hvis anamnese, kliniske funn og/eller MR-funn indikerer kardioembolisk infarkt, utredes pasienten med 24-timers EKG-registrering og ekkokardiografi. Som

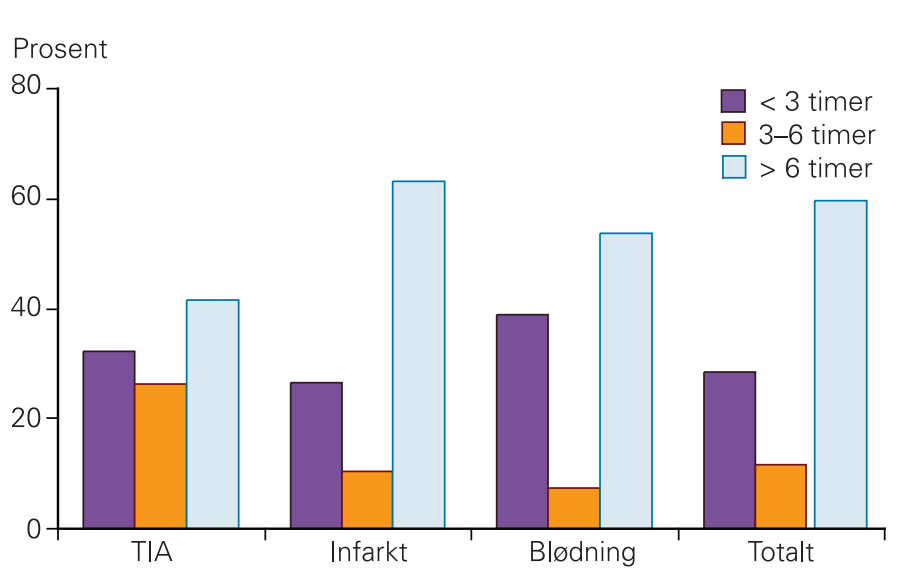

Figur 1 Tid fra symptomdebut til innleggelse i sykehus for pasienter med transitorisk iskemisk anfall (TIA), infarkt og blødning. Prosentandel i forhold til klinisk gruppering ment criteria) som mikroangiopatisk (småkarsykdom), aterosklerotisk (storkarsykdom), kardioembolisk (hjertesykdom), eller ukjent/ andre/multiple årsaker. Primære hjerneblødninger klassifiseres etter lokalisasjon og volum, blødningsetiologien etter grunnleggende eller utløsende årsak (15).

Informert samtykke ble innhentet av lege, vanligvis 1-2 dager etter innleggelse da diagnosen cerebrovaskulær sykdom var sikker. Pasienten fikk informasjon om studien og ble forespurt om å signere samtykke til datalagring og forskning. Hvis pasienten ikke hadde samtykkekompetanse, fikk pårørende informasjon om studien og ble eventuelt bedt om å signere på vegne av pasienten. Bergen Stroke Registry og Bergen Stroke Study er godkjent av Regional etisk komité og Norsk samfunnsvitenskaplig datatjeneste (NSD).

Følgende statistiske tester ble benyttet: T-test for kontinuerlige variabler, Fishers eksakte test og khikvadrattest for kategoriske variabler. Alle analyser ble gjort ved hjelp av Stata versjon 11.0.

\section{Resultater}

Fra februar 2006 til april 2009 ble det innlagt 1104 pasienter med sikker cerebrovaskulær sykdom. Tre pasienter ønsket ikke å være med i studien. Studieutvalget består derfor av 1101 pasienter, deriblant 464 (42,1\%) kvinner. $108(9,8 \%)$ av pasientene fikk diagnosen hjerneblødning, $873(79,3 \%)$ hjerneinfarkt og $120(10,9 \%)$ transitorisk iskemisk anfall. Gjennomsnittlig alder var 72 (spredning 18-98) år. Demografiske karakteristika er beskrevet i tabell 1. I den representative populasjonen fra eget nedslagsfelt var det $47 \%$ kvinner, gjennomsnittsalder var 74 år, $16 \%$ var under 60 år. Median liggetid i slagenheten var for pasienter med TIA 2,5 døgn, infarkt 6,5 døgn og blødning 8,9 døgn. Etiologisk klassifisering av pasientene med iskemi fremgår av tabell 2.

Tid fra symptomdebut til innleggelse i sykehus for pasienter med TIA, infarkt og blødning fremgår av figur 1. Symptomdebut var kjent for $668(61 \%)$ av pasientene. $29 \%$ av pasientene ankom innen tre timer etter symptomdebut og $41 \%$ innen seks timer. Median tid fra symptomdebut til innleggelse var 194 minutter (ved TIA 200 minutter, ved infarkt 211 minutter og ved blødning 115 minutter).

Ved innleggelse hadde $72 \%$ av slagpasientene lette eller ingen nevrologiske utfall (NIHSS 0-7) (fig 2) (16). Med en ren klinisk TIA-definisjon (TIA med MR-diffusjonsavvik flyttet fra infarktgruppen til TIAgruppen) hadde $71 \%$ av infarktpasientene NIHSS $0-7$. Moderate til alvorlige utfall (NIHSS $\geq 8$ ), som indikerte behov for et lengre rehabiliteringsopphold eller langtidspleie, var til stede hos $29 \%$ av pasientene totalt (3\% med TIA, 30\% med infarkt og $66 \%$ med blødning).

I en representativ tremånedersperiode, 1.2.-30.4 . 2009, ble det innlagt 217 pasien- 
ter med spørsmål om cerebrovaskulær sykdom, hvorav 108 (49,8 \%) hadde andre sykdommer.

Intravenøs trombolytisk behandling med vevsplasminogenaktivator (tPA) ble gitt til $15,3 \%$ av pasientene med hjerneinfarkt og til $58 \%$ av dem som ankom innen tidsgrensen for trombolytisk behandling (4 1/2 time).

$37(3,4 \%)$ pasienter døde i løpet av den første uken etter symptomdebut, 22 (2,5\%) av dem med infarkt og $15(13,9 \%)$ av dem med blødning. Ingen pasienter med transitorisk iskemisk anfall døde. Sju dager etter symptomdebut var $63 \%$ av pasientene uavhengig i dagliglivet (mRS 0-2) (fig 3). Andelen var høyere hos pasienter med iskemi $(67 \%)$ enn hos pasienter med blødning (23\%). $25 \%$ av pasientene hadde behov for hjelp (mRS 3-4) og 9\% var sengeliggende og helt pleietrengende (mRS 5). Etter eksklusjon av pasienter med transitorisk iskemisk anfall og pasienter som døde, var $61 \%$ uavhengige, $29 \%$ hadde behov for hjelp og $10 \%$ var helt pleietrengende. 56 hadde MRfunn forenlig med infarkt, men med klinisk presentasjon som ved TIA. Når disse og øvrige TIA-pasienter samt de som døde, ble ekskludert fra analysen, var $61 \%$ uavhengige, $29 \%$ avhengig av hjelp og $10 \%$ pleietrengende (fig 4). Etter at pasienter $<60$ år innlagt fra annet sykehusområde ble eksludert fra analysen, var andelen selvhjulpne pasienter i den representative populasjonen fortsatt over $50 \%$.

\section{Diskusjon}

Ved innleggelsen hadde det store flertallet $(72 \%)$ av våre pasienter ingen eller lette nevrologiske utfall. Disse pasientene må utredes, overvåkes og behandles med samme intensitet som pasienter med manifeste alvorlige utfall, men vil ha lite behov for rehabilitering i sykehus. Slagenhetsstudiene synes gjennomgående å ha selektert pasienter med manifeste alvorlige slag med behov for rehabilitering. En stor gruppe pasienter med akutte cerebrovaskulære sykdommer er derfor mangelfullt representert i slagenhetsstudiene.

I vår studie hadde ca. $10 \%$ av pasientene transitorisk iskemisk anfall. I slagenhetsstudien fra Trondheim (17) hadde ca. 3\% av pasientene TIA, i slagenhetsstudien fra Akershus universitetssykehus (18) var TIA et eksklusjonskriterium. TIA-pasientene er mangelfullt representert i slagenhetsstudiene, og studiene gir ikke et riktig bilde av iskemisk cerebrovaskulær sykdom. Det er enighet om at pasienter med TIA skal utredes og behandles raskt, men det er uenighet om innleggelse alltid er nødvendig.

$\mathrm{ABCD} 2$-skår er utviklet for å stratifisere risiko for hjerneinfarkt og identifisere pasienter som ikke trenger umiddelbar sykehusinnleggelse. Med ABCD2-skår vil man imidlertid miste en del reelle iskemiske episoder (19) og risikoprofilen hos den enkelte pasient kan være vanskelig å definere. Man

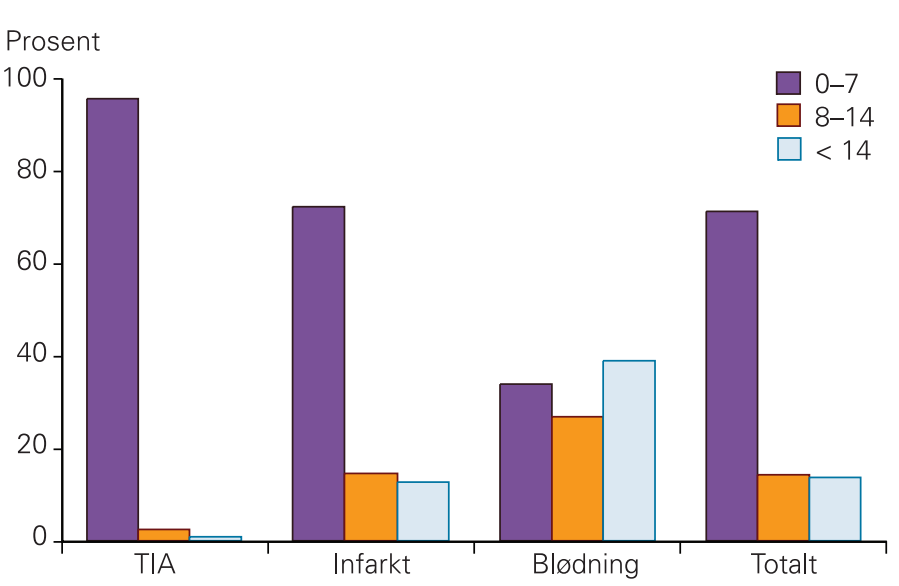

Figur 2 National Institutes of Health Stroke Scale (NIHSS) (16) ved innleggelse hos pasienter med TIA, hjerneinfarkt eller hjerneblødning. NIHSS 0-7 = lette utfall, NIHSS 8-14 = moderate utfall, NIHSS $\geq 15$ = alvorlige utfall

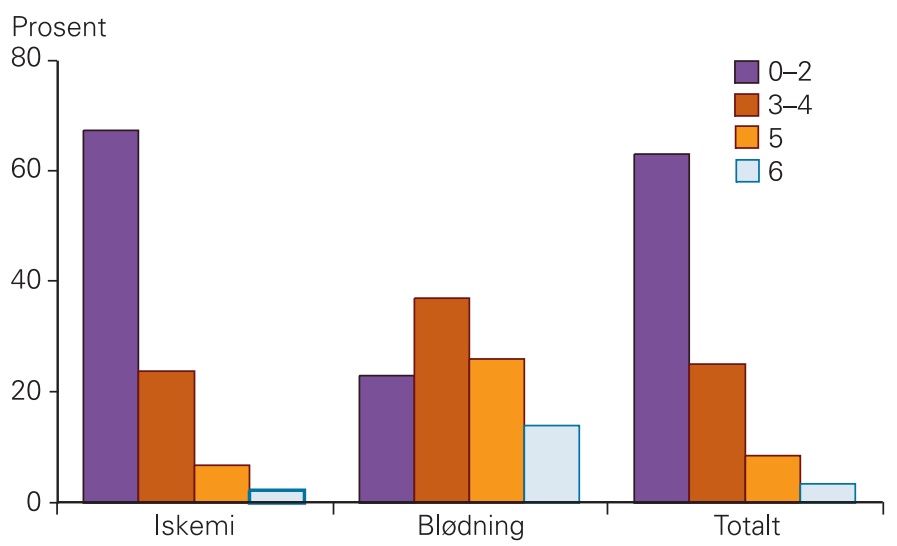

Figur 3 Modifisert Rankins skala (mRS) (6) sju døgn etter symptomdebut. mRS 0-2 = uavhengig, $m R S 3-4=$ avhengig av hjelp, $m R S 5=$ sengeliggende, $m R S 6=d ø d$.

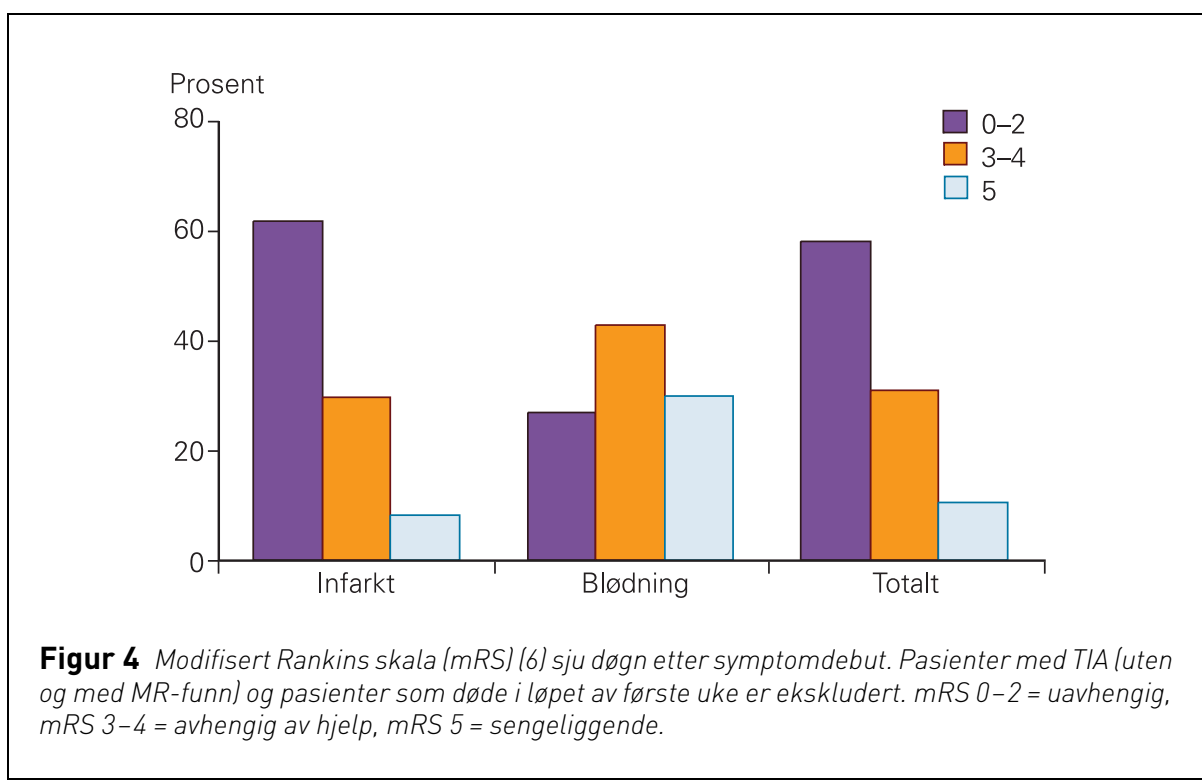


har fra St. Olavs hospital nylig anbefalt at pasienter med en skår på $\geq 5$ skal innlegges akutt, mens de med skår $<5$ kan vurderes poliklinisk i løpet av tre dager (20). Anbefalingen ble raskt endret til at pasienter med en skår på $<4$ kan vurderes poliklinisk i løpet av 1-3 dager (21). I Helsedirektoratets retningslinjer fra 2010 anbefales det samme (22). En 59 år gammel mann (skår 0) med uttalte pareser i ansikt, arm eller bein (skår 2) av 55 minutters varighet (skår 1) faller under anbefalt grense for innleggelse. American Heart Association anbefaler en grense på $\geq 3$ for innleggelse (14). I disse faller en 59 år gammel mann (skår 0) med global afasi (skår 1) av 55 minutters varighet (skår 1) under anbefalt grense. Med den usikkerheten som hefter ved ABCD2-skår, ser vi ikke grunn til å ekskludere TIA-pasienter fra umiddelbar innleggelse på grunnlag av anamnestiske opplysninger. I vår studie ble alle pasienter med mulig TIA innlagt, i overensstemmelse med anbefalinger fra European Stroke Organisation (23). Vi benyttet MR i diagnostikken og antar at vi har fanget opp alle transitorisk iskemisk anfall i vår populasjon.

Rundt $40 \%$ av alle slagpasienter i denne studien ble innlagt innen seks timer etter symptomdebut. I slagenhetsstudiene ble pasientene per protokoll vanligvis inkludert innen 7-14 døgn og i bare tre studier innen ett døgn etter symptomdebut $(17,24,25)$. I flertallet av studiene er det ikke angitt tid før innleggelse eller inklusjon. Korteste gjennomsnittlige tid har vært henholdsvis sju timer (25), 12 timer (26), 13 timer (18) eller 16,5 timer (17) etter symptomdebut. Slagenhetsstudiene gir derfor ikke relevante data om kliniske funn, diagnostikk eller behandling de første timene.

I den totale populasjonen var gjennomsnittsalderen 72 år, og $22 \%$ av pasientene var yngre enn 60 år. I den representative tremånederspopulasjonen var gjennomsnittsalderen 74 år, og $16 \%$ av pasientene var yngre enn 60 år. I metaanalysen fra Stroke Unit Trialists' Collaboration (1) var pasientenes gjennomsnittlige alder i forskjellige studier 60-80 år. Imidlertid angis pasientens gjennomsnittlige alder eller aldersgrense nedad i bare halvparten av studiene, og det er derfor ikke mulig å se om studiene omfattet også yngre pasienter. Vi har tidligere vist at det ofte er andre differensialdiagnostiske og etiologiske problemstillinger hos yngre slagpasienter enn hos eldre, og de sosiale konsekvensene er annerledes (27-30). En slagenhet må nødvendigvis kunne ta helhetlige vurderinger også hos yngre mennesker med hjerneslag.

Rundt halvparten av pasientene som var innlagt med spørsmål om hjerneslag, viste seg å ha andre diagnoser enn slag. Dette er høyere enn hva som er funnet $i$ andre studier, der andel feildiagnoser er angitt til 19-27\% (31). Forskjellen kan skyldes at pasientene i vår studie ble innlagt direkte og ikke via lege/legevakt. En lav terskel for innleggelse er allikevel nødvendig for å fange opp flest mulig cerebrovaskulære hendelser.

Cerebral CT gir mangelfull informasjon ved hjerneinfarkt de første timene når terapeutisk avgjørelse skal tas. I en subgruppeanalyse av 561 konsekutive pasienter med hjerneinfarkt fant vi tidlige iskemiforandringer hos bare $29 \%$ (10). Allikevel er CT nyttig for å utelukke blødning. CT-angiografi i tillegg til standard CT gir informasjon om okklusjonens lokalisasjon og størrelse. Klinisk undersøkelse er her ikke tilstrekkelig (32). CT-angiografi gir derfor det rasjonelle grunnlaget for å vurdere alternative behandlingsregimer, som intraarteriell intervensjon.

I den etiologiske utredningen er MR nødvendig for en eksakt diagnose $(10,11)$. Vi har tidligere vist at MR er nødvendig for å klassifisere hjerneinfarktene (10). I en subgruppeanalyse av 419 pasienter med klinisk lakunært syndrom (småkarsykdom) viste diffusjons-MR at $40,5 \%$ av pasientene hadde et ikke-lakunært embolisk infarkt (10). Denne differensieringen har direkte terapeutisk betydning (antikoagulasjon versus platehemming). I dag blir derfor $85 \%$ av våre pasienter med hjerneinfarkt undersøkt med MR.

Ultraydundersøkelser utføres rutinemessig hos pasienter med TIA eller infarkt. Vi har tidligere vist at ultralydundersøkelser er klinisk nyttig $(12,28,33)$ både for akutt og sekundærprofylaktisk behandling. Denne studien (tab 2) viser at kardiogene embolier var hyppigere årsaken ved infarkt enn ved TIA, mens aterosklerose var hyppigere ved TIA. Dupleksundersøkelse av carotisarteriene gir informasjon om grad av aterosklerose. Transkranial dupleksundersøkelse gir hemodynamisk tilleggsinformasjon om konsekvenser av stenoser og okklusjoner og om sirkulerende embolier. Ultralyd er derfor et nødvendig supplement til MR- og CT-angiografi.

I tråd med anbefalinger fra Stroke Unit Trialists' Collaboration ble rehabilitering startet tidlig og generell støttebehandling gitt ved behov. Etter én uke var én av ti pasienter rent pleietrengende, nær $1 / 3$ hadde behov for langvarig rehabilitering, mens $>50 \%$ av pasientene var selvhjulpne (mRS $0-2)$. Andelen selvhjulpne pasienter er høyere enn i mange andre serier. Økende alder er assosiert med større funksjonshemning etter et slag, og aldersfordelingen $\mathrm{i}$ populasjonen vil derfor påvirke andelen som blir selvhjulpne. Etter korreksjon for overrepresentasjon av unge slagpasienter var andelen selvhjulpne pasienter etter en uke fortsatt mer enn $50 \%$. Flertallet av cerebrovaskulære pasienter har derfor ikke behov for lengre sykehusopphold med kompleks tverrfaglig rehabilitering.

Liggetiden i slagenheten er avhengig av slagets alvorlighet. I denne studien er som forventet liggetiden høyere ved hjerneblødning (median 8,9 døgn) enn ved hjerneinfarkt (median 6,5 døgn). Det er anbefalt at gjennomsnittlig liggetid bør være «minimum 1 uke, vanligvis $1-3$ uker» (3). En slik anbefaling er sannsynligvis relevant for pasienter selektert for rehabilitering. Rundt halvparten av pasientene med hjerneinfarkt $\mathrm{i}$ vår studie hadde en liggetid på under sju døgn. Helsedirektoratets retningslinjer 2010 anfører at så kort gjennomsnittlig liggetid «ikke kan anbefales» (22). Retningslinjene er her ikke $\mathrm{i}$ overensstemmelse med våre erfaringer.

\section{Konklusjon}

Akutt hjerneinfarkt krever i dag rask diagnostikk. Målet er umiddelbar rekanaliserende behandling. Slagenheten må sikre at pasienten når dette målet. Nær $3 / 4$ av alle pasienter med akutt cerebrovaskulær sykdom har ved innleggelsen lette nevrologiske utfall. Etter en uke er flertallet av pasientene selvhjulpne. En akutt slagenhet må ha fokus også på pasienter som har lette eller ingen nevrologiske utfall for å skreddersy sekundærprofylakse. Den rehabiliteringsorienterte slagenheten er en nødvendig, men ikke en tilstrekkelig, forutsetning for dagens slagmedisin.

Oppgitte interessekonflikter: Lars Thomassen har mottatt forelesningshonorar og kongresstøtte fra Boehringer Ingelheim Norway. Ulrike WajeAndreassen har vært invitert til europeiske slagkongresser av Boehringer Ingelheim. Jan Brøgger har mottatt foredragshonorar og reisestøtte til kongress fra Pfizer. Halvor Næss har ingen oppgitte interessekonflikter.

\section{Litteratur}

1. Stroke Unit Trialists' Collaboration. Organised inpatient (stroke unit) care for stroke. Cochrane Database Syst Rev 2007; nr. 4: CD000197.

2. Langhorne P, Pollock A. What are the components of effective stroke unit care? Age Ageing 2002; 31 : 365- 71 .

3. Indredavik B. En effektiv slagenhet - hva er det? Tidsskr Nor Lægeforen 2007: 127: 1214-8.

Thomassen L, Waje-Andreassen U, Næss H. Utredning og behandling av nevrovaskulære sykdommer. Metodebok. Bergen: Nevrologisk avdeling, Haukeland universitetssykehus, 2010

5. Thomassen L, Waje-Andreassen U, Naess $\mathrm{H}$ et al. Long-term effect of intravenous thrombolytic therapy in acute stroke: responder analysis versus uniform analysis of excellent outcome. Cerebrovasc Dis 2005; 20: $470-4$

6. Wilson JT, Hareendran A, Grant M et al. Improving the assessment of outcomes in stroke: use of a structured interview to assign grades on the modified Rankin Scale. Stroke 2002; 33: 2243-6.

Thomassen L. Behandling av akutt hjerneinfarkt. Tidsskr Nor Lægeforen 2007: 127: 1060-3.

8. Thomassen L, Bakke SJ. Endovascular reperfusion therapy in acute ischaemic stroke. Acta Neurol Scand Suppl 2007; 187: 22-9

9. Waje-Andreassen U, Thomassen L, Smievoll Al. Tidlige CT-tegn ved akutt cerebral iskemi. Tidsskr Nor Lægeforen 2001; 121: 1591-3.

10. Naess H, Brogger JC jr, Idicula T et al. Clinical presentation and diffusion weighted MRI of acute cerebral infarction. The Bergen Stroke Study. BMC Neurol 2009. 9: 44.

11. Rønning OM. Hvordan stille diagnosen akutt hjerneslag? Tidsskr Nor Lægeforen 2007; 127: $888-91$

12. Thomassen L, Waje-Andreassen $U$, Naess $\mathrm{H}$ et al Combined carotid and transcranial ultrasound findings compared with clinical classification and stroke severity in acute ischemic stroke. Cerebrovasc Dis 2006; 21: 86-90. 
13. Næss H, Waje-Andreassen U, Thomassen L. Overvåking ved akutt hjerneinfarkt. Tidsskr Nor Lægeforen 2006; 126: 444-6.

14. Easton JD, Saver JL, Albers GW et al. Definition and evaluation of transient ischemic attack: a scientific statement for healthcare professionals from the American Heart Association/American Stroke Association Stroke Council; Council on Cardiovascular Surgery and Anesthesia; Council on Cardiovascular Radiology and Intervention; Council on Cardiovascular Nursing; and the Interdisciplinary Council on Peripheral Vascular Disease. The American Academy of Neurology affirms the value of this statement as an educational tool for neurologists. Stroke 2009; 40: $2276-93$.

15. Rønning P, Sorteberg W, Nakstad P et al. Aspects of intracerebral hematomas-an update. Acta Neurol Scand 2008; 118: 347-61.

16. Brott T, Adams HP Jr, Olinger CP et al. Measurements of acute cerebral infarction: a clinical examination scale. Stroke 1989; 20: 864-70.

17. Indredavik B, Bakke F, Solberg R et al. Benefit of a stroke unit: a randomized controlled trial. Stroke 1991; 22: 1026-31.

18. Rønning OM, Guldvog B. Stroke unit versus general medical wards, II: neurological deficits and activities of daily living: a quasi-randomized controlled trial. Stroke 1998; 29: 586-90.

19. Quinn TJ, Cameron AC, Dawson J et al. ABCD2 scores and prediction of noncerebrovascular diagnoses in an outpatient population: a case-control study. Stroke 2009; 40: 749-53.

20. Indredavik B, Bakke F, Slordahl SA et al. Stroke unit treatment. 10-year follow-up. Stroke 1999; 30: 1524-7.

21. Ellekjær H, Dahl T. Risikoskår og TIA-pasienter. Tidsskr Nor Legeforen 2010; 130: 14.

22. Helsedirektoratet. Nasjonal retningslinje for behandling og rehabilitering ved hjerneslag. www.helsedir.no/publikasjoner (1.7.2010).

23. European Stroke Organisation (ESO) Executive CommitteeESO Writing Committee. Guidelines for management of ischaemic stroke and transient ischaemic attack 2008. Cerebrovasc Dis 2008; 25 : 457-507.

24. Spengos K, Tsivgoulis G, Manios E et al. Which patients benefit most from treatment in a stroke unit? Stroke 2004; 35: 294

25. Sulter G, Elting JW, Langedijk $M$ et al. Admitting acute ischemic stroke patients to a stroke care monitoring unit versus a conventional stroke unit: a randomized pilot study. Stroke 2003; 34: 101-4.

26. Strand T, Asplund K, Eriksson S et al. Stroke unit care-who benefits? Comparisons with general medical care in relation to prognostic indicators on admission. Stroke 1986; 17: 377-81.

27. Waje-Andreassen U, Naess $H$, Thomassen $L$ et al. Arterial events after ischemic stroke at a young age: a cross-sectional long-term follow-up of patients and controls in western Norway. Cerebrovasc Dis 2007; 24: 277-82.

28. Thomassen L, Waje-Andreassen U, Naess H. Early ischemic CT changes before thrombolysis: The influence of age and diabetes mellitus. Ther Clin Risk Manag 2008; 4: 699-703.

29. Thomassen L, Waje-Andreassen U, Næss $\mathrm{H}$ et al. Trombolytisk behandling ved hjerneinfarkt. Tidsskr Nor Lægeforen 2002; 122: 2095-7.

30. Naess H, Waje-Andreassen $U$, Thomassen $L$ et al. Do all young ischemic stroke patients need longterm secondary preventive medication? Neurology 2005; 65: 609-11.

31. Rønning OM, Thommessen B. Når hjerneslagdiagnosen er feil. Tidsskr Nor Lægeforen 2005; 125: $1655-7$.

32. Maas MB, Furie KL, Lev MH et al. National Institutes of Health Stroke Scale score is poorly predictive of proximal occlusion in acute cerebral ischemia. Stroke 2009; 40: 2988-93.

33. Thomassen L, Waje-Andreassen U, Naess $\mathrm{H}$ et al. Doppler ultrasound and clinical findings in patients with acute ischemic stroke treated with intravenous thrombolysis. Eur J Neurol 2005; 12: 462-5. 